\title{
A comparative in vitro study on fluoride release and water sorption of different flowable esthetic restorative materials
}

\author{
Asmaa Youssif Harhash ${ }^{1}$, Iman Ibrahim ElSayad ${ }^{2}$, Ahmad G. S. Zaghloul ${ }^{3}$
}

Correspondence: Dr. Iman Ibrahim ElSayad

Email: imsayad@gmail.com

\begin{abstract}
'Department of Conservative Dentistry, Faculty of Dentistry, Egyptian Russian University, Cairo, Egypt, ${ }^{2}$ Department of Conservative Dentistry, Faculty of Oral and Dental Medicine, Cairo University, Cairo, Egypt, ${ }^{3}$ Department of Conservative Dentistry, Faculty of Dentistry, British University in Egypt, Cairo, Egypt
\end{abstract}

\section{ABSTRACT}

Objectives: The objective of the study was to evaluate fluoride release and water sorption of three flowable esthetic restorative materials: a giomer, a fluoride-releasing resin composite, and a nonfluoridated resin composite. Materials and Methods: Ten samples from a giomer, a fluoride releasing nano-hybrid, and a nonfluoridated nano-hybrid composite were prepared and immersed in deionized water. Fluoride measurements were done using an ion-specific electrode attached to a microprocessor-based fluoride meter after 1 day, 1 week, and 4 weeks. Another thirty samples were made and placed in desiccators. Water sorption was calculated by weighing the specimens before and after water immersion for 1 day, 1 week, and 4 weeks. Data analysis was done using two-way ANOVA, paired $t$-test $(P<0.05)$, and Pearson's correlation coefficient to calculate correlations between fluoride release and water sorption. Results: The highest fluoride release was from giomer after 1 day, it was statistically significant from all other groups. Both nano-hybrid composites after 1 day showed significantly lower water sorption which was different than all the other groups. Pearson's correlation showed no significant correlations between fluoride release and water sorption. Conclusions: Fluoride release is material and time dependent, while water sorption is material dependent.

Key words: Fluoride release, giomer, nano-hybrid composite, water sorption

\section{INTRODUCTION}

Fluoride-containing restorative materials have been used routinely since the introduction of glass ionomer cements (GIC). Direct restorative materials such as resin composites, GIC, resin-modified GIC (RMGIC), and prereacted glass-ionomers or giomers have different fluoride quantities and release rates. Giomers are categorized as hybrids of GIC and resin composite combining the characteristics of release and recharge of fluorides from GIC, with

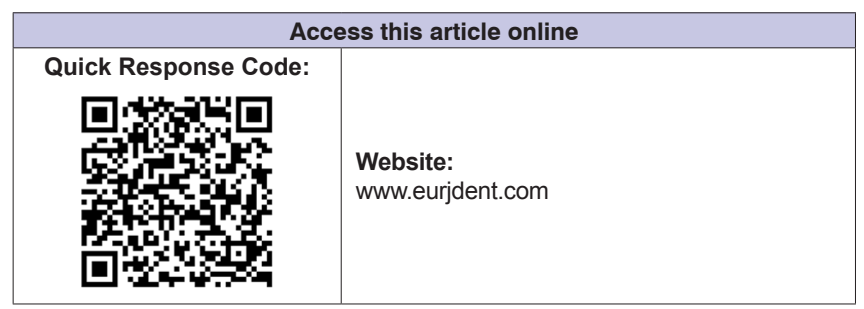

excellent esthetics, polishability, and strength from resin composites. ${ }^{[1]}$ Second-generation giomers use surface prereacted glass-ionomer (SPRG) filler technology, in which the glass filler surface reacts with polyacrylic acid during water presence to give a thick siliceous hydrogel layer. ${ }^{[2]}$ The released and recharged fluorides from giomers are due to this hydrogel layer. ${ }^{[1]}$ From a clinical point of view, a

This is an open access article distributed under the terms of the Creative Commons Attribution-NonCommercial-ShareAlike 3.0 License, which allows others to remix, tweak, and build upon the work non-commercially, as long as the author is credited and the new creations are licensed under the identical terms.

For reprints contact: reprints@medknow.com

How to cite this article: Harhash AY, EISayad II, Zaghloul AG.
A comparative in vitro study on fluoride release and water sorption
of different flowable esthetic restorative materials. Eur J Dent
$2017 ; 11: 174-9$.
DOI: $10.4103 /$ ejd.ejd_228_16


material with high release and rechargability of fluoride, in addition to high compressive strength forms a better restoration. Recently, a flowable giomer plus restorative material was introduced with claims of combining flowability with the strength, durability, and esthetics of hybrid composites. Flowable resinous restorations, in general, have the advantage of high flexibility which minimizes the shrinkage stress problem. In addition, their low viscosity permits them to make a better linkage to both enamel and dentin and to be more adapted.

The optimum fluoride level needed to stop caries progression remains unknown. However, providing a source for maintained fluoriderelease from a restoration would be beneficial. Fluoridated and nonfluoridated resin composites release less fluoride than GIC, RMGIC, polyacid-modified resin composites, and giomers. ${ }^{[2]}$ Fluoride recharge and rerelease was proven form GIC, giomer, and fluoridated resin composites. ${ }^{[3]}$ Scarce data are available on whether nonfluoridated resin composites could release detectable amounts of fluoride and subsequently recharged. Thus, proving fluoride release capabilities of a nonfluoridated resin composite would be interesting.

The interaction between restorative materials and oral fluids is inevitable. Fluid uptake by resin-based restorations is a major outcome of this interaction. Fluid sorption combines adsorption and absorption. Adsorption indicates adherence of liquid molecules to a solid material surface. Absorption involves penetration of liquid molecules into a solid structure mainly through diffusion. Water sorption by resin-based restorations is a diffusion-controlled process, and the water uptake occurs largely in the resin matrix. ${ }^{[4]}$ Uptake of fluids within resin-based restorations could relieve residual polymerization shrinkage stresses. ${ }^{[5]}$ However, it negatively affects physico-mechanical properties, color stability, and bond strength, thus reducing the material's durability. ${ }^{[6]}$

Fluoride is released from restorations by diffusion within an absorbed aqueous medium. Fluoride release is, therefore, mediated by an ability to allow water diffusion. ${ }^{[7]}$ The ability of restorative materials to support diffusion while maintaining structural integrity is equally important to the ability of fluoride release. This enables the material to function properly without having excessive sorption, which may cause swelling of the resin matrix and generate pressure within the material or on surrounding tooth structure. Although water sorption may cause fluoride release in some restorative materials, ${ }^{[8]}$ information about the relation between fluoride release and water sorption of resin-based restorative materials is still few. This study focused on fluoride release and water sorption of three flowable restorative materials at 3 time periods. The first null hypothesis tested was that restorative materials will release similar fluoride amounts at tested time periods. The second null hypothesis was that no difference in water sorption will exist between restorative materials.

\section{MATERIALS AND METHODS}

\section{Materials}

Two fluoride-releasing restorative materials, Beautifil Flow Plus and Tetric N-Flow and one nonfluoridated resin composite, G-aenial Universal Flo were selected. Their composition, manufacturers, and lot numbers are summarized in Table 1.

\section{Preparation of fluoride release test samples}

Thirty disc-shaped samples, ten from each restorative material $(n=10)$, were prepared according to manufacturer's instructions in a specially constructed Teflon mold (6 mm diameter and $3 \mathrm{~mm}$ thickness).

\begin{tabular}{|c|c|c|c|c|}
\hline Material & Description & Composition & Manufacturer & Lot number \\
\hline $\begin{array}{l}\text { Beautifil Flow Plus } \\
\text { - Shade A2 (F03) }\end{array}$ & $\begin{array}{l}\text { Fluoride-releasing } \\
\text { flowable giomer }\end{array}$ & $\begin{array}{l}\text { Base: Bis-GMA/TEGDMA resin } \\
\text { Filler: Multifunctional glass filler and SPRG filler } \\
\text { based on fluoroboroaluminosilicate glass. Particle } \\
\text { size }(0.01-4.0 \mu \mathrm{m}) \text {, filler loading: } 66.8 \mathrm{wt} \%\end{array}$ & SHOFU Inc. Kyoto, Japan & 041004 \\
\hline $\begin{array}{l}\text { Tetric N-Flow } \\
\text { Shade - A2 }\end{array}$ & $\begin{array}{l}\text { Fluoride releasing } \\
\text { flowable nano-hybrid } \\
\text { resin composite }\end{array}$ & $\begin{array}{l}\text { Matrix: Bis-GMA, UDMA, TEGDMA } 35.1 \mathrm{wt} \% \\
\text { Filler: Barium glass, ytterbium trifluoride, mixed } \\
\text { oxide, silicon dioxide }(0.6 \mu \mathrm{m}), 63.8 \mathrm{wt} \% \\
\text { Additives, stabilizers, catalysts, pigments } 1.1 \mathrm{wt} \%\end{array}$ & $\begin{array}{l}\text { Ivoclar Vivadent, Schaan, } \\
\text { Liechtenstein }\end{array}$ & 606957 \\
\hline $\begin{array}{l}\text { G-aenial Universal } \\
\text { Flo - Shade A2 }\end{array}$ & $\begin{array}{l}\text { Nonfluoridated } \\
\text { flowable nano-hybrid } \\
\text { resin composite }\end{array}$ & $\begin{array}{l}\text { Matrix: UDMA, Bis-MEPP, TEGDMA, } 31 \mathrm{wt} \% \\
\text { Filler: Silicon dioxide }(0.016 \mu \mathrm{m}) \text {, strontium glass } \\
(0.2 \mu \mathrm{m}), 69 \mathrm{wt} \% \text {. Pigment, photoinitiator trace }\end{array}$ & GC Corporation Tokyo, Japan & 1107041 \\
\hline
\end{tabular}


The mold was applied on a glass plate and a celluloid matrix and packed with the restorative material. Another celluloid strip and glass plate were used to cover the mold. A $500 \mathrm{~g}$ weight was placed for $1 \mathrm{~min}$ on top, and excess extruded material was then carefully removed. Samples were cured using light-emitting diode light cure (Elipar S10, 3M ESPE, D-82229 Seefeld, Germany) at $1200 \mathrm{~mW} / \mathrm{cm}^{2}$ for $40 \mathrm{~s}$ from both sides. Samples were removed, inspected, and kept in an incubator at $37^{\circ} \mathrm{C}$ and $100 \%$ relative humidity for $1 \mathrm{~h} .{ }^{[2]}$

\section{Fluoride concentration measurements}

Each sample was suspended with a nonfluoridated dental floss in $4 \mathrm{ml}$ deionized water in a plastic tube. Tubes were placed in an incubator at $37^{\circ} \mathrm{C} \pm 0.5^{\circ} \mathrm{C}$ during the test period. Rubber stoppers were used to cover tubes to prevent water evaporation. After $24 \mathrm{~h}$, the tubes were shaken, samples were held with a metal forceps, and each sample was rinsed using $1 \mathrm{ml}$ of deionized water poured from a small pipette and added to the original $4 \mathrm{ml}$ in the plastic tube to be analyzed. Samples were then suspended in other plastic tubes having $4 \mathrm{ml}$ of fresh deionized water each and changed daily for 4 weeks. Solutions were also analyzed after 1 and 4 weeks after collecting them as described above.

Fluoride analysis was done using an ion-specific electrode (FC 301 B, Hanna Company, Italy) connected to a microprocessor-based portable fluoride meter (HI 98401, Hanna Company, Italy). To check the electrode potential, calibration of the meter was done at a temperature of $20^{\circ} \mathrm{C} \pm 3^{\circ} \mathrm{C}$ using two standard fluoride calibration solutions: HI $70701(10 \mathrm{mg} / \mathrm{L}$ Fl solution) and HI 70703 (100 mg/L Fl solution). A temperature probe (HI 7662, Hanna Company, Italy) connected to the meter was used to measure and adjust the temperature of deionized water. The readings appeared on the lower part of the liquid crystal display (LCD). A reference electrode (HI 7663, Hanna Company, Italy) was also attached to the fluoride meter and immersed in deionized water during fluoride measurement to ensure a correct and repeatable reading each time. ${ }^{[9]}$

The $4 \mathrm{ml}$ storage solution of each sample in addition to the $1 \mathrm{ml}$ deionized water used for rinsing were applied on $0.5 \mathrm{ml}$ of ready-made total ionic strength adjustment buffer II solution TISAB II (HI 4010-05, Hanna Company, Italy) with a ratio of 10:1 to provide a background of constant ionic strength for fluoride measurement. TISAB II contains $2 \% 1.2$ cyclohexane diamine tetra acetic acid, a metal chelating agent, that preferentially decomplex fluoride from the polyvalent cations, to make fluoride available for measuring. ${ }^{[10]}$ It was then placed in a specially fabricated Teflon pot (beaker) with three holes cover. The beaker held the three electrodes far from each other and from its bottom. The electrodes were completely submerged in the solution to ensure a correct fluoride measurement in deionized water. The readings are shown on the upper part of LCD in ppm. ${ }^{[9]}$

\section{Preparation of water sorption test samples}

Samples were fabricated following ISO 4049-2009(E): polymer-based restorative materials. ${ }^{[11]}$ Ten discs from each restorative material were prepared in a cylindrical Teflon mold (15 mm diameter and $1 \mathrm{~mm}$ thickness) at $23^{\circ} \mathrm{C} \pm 2{ }^{\circ} \mathrm{C}$. The mold was packed with the restorative material as described previously and cured at five locations for $40 \mathrm{~s}$ each till the whole surface was cured. Total curing time was similar for all samples.

\section{Water sorption measurements}

Samples were removed from the mold and placed in a desiccator containing silica gel maintained at $37^{\circ} \mathrm{C}$ for $22 \mathrm{~h}$. Samples were then taken to a second desiccator at $23^{\circ} \mathrm{C} \pm 2^{\circ} \mathrm{C}$ for $2 \mathrm{~h} .{ }^{[12]}$ Samples were removed, placed on a filter paper for one min, and weighed to an accuracy of $\pm 0.1 \mathrm{mg}$ with a digital electronic sensitive balance (SIGMA-ALDRICH, Germany). This cycle was repeated till the weight change did not exceed $0.2 \mathrm{mg}$ and a constant mass $\left(\mathrm{m}_{1}\right)$ was gained. A pilot study was done to determine the time needed to obtain a constant mass, which was 2 weeks. Samples were stored individually in glass tubes containing $15 \mathrm{ml}$ of deionized water for $24 \mathrm{~h}$. Samples were then taken out, blot-dried with absorbent paper, air-dried for $15 \mathrm{~s}$, and reweighed to obtain $\mathrm{m}_{2}$. Samples were restored again in deionized water for 1 week to record $\mathrm{m}_{3}$ and for 4 weeks to record $\mathrm{m}_{4}$.

The volume (V) of samples was calculated by taking their diameters at two opposing points on the sample circumference with a digital caliper (CD6CS, Mitutoyo, Kanagawa, Japan), and their thickness at the center and at four equally spaced points with a digital micrometer (102-125, Mitutoyo, Kanagawa, Japan). Sorption was calculated as follows:

- Sorption after 1 day $\left(S_{1 d}\right)=\left(m_{2}-m_{1} / V\right)$

- Sorption after 1 week $\left(\mathrm{S}_{1 \mathrm{w}}\right)=\left(\mathrm{m}_{3}-\mathrm{m}_{1} / \mathrm{V}\right)$

- Sorption after 4 weeks $\left(\mathrm{S}_{4 \mathrm{w}}\right)=\left(\mathrm{m}_{4}-\mathrm{m}_{1} / \mathrm{V}\right)$.

\section{Statistical analysis}

Data were analyzed using SPSS software version 16.0 (SPSS Inc., Chicago, IL, USA). Normality 
of the data distribution was checked, and parametric tests were chosen since data were distributed normally. Data were analyzed using two-way ANOVA test and paired $t$-test, where the probability level was set at $\alpha=0.05$. Pearson's correlation coefficient was used to calculate significant correlations between fluoride release and water sorption.

\section{RESULTS}

\section{Fluoride release}

Table 2 shows the fluoride release of the tested groups. Two-way ANOVA test revealed that material, time, and their interaction had a statistical significant effect on fluoride release. Statistical significant difference was found between giomer and nano-hybrid composites, as giomer released statistically higher amounts of fluoride $(P<0.05)$. For all materials, the amount of fluoride release decreased significantly with time.

\section{Water sorption}

Table 3 shows the results of water sorption test. Two-way ANOVA test showed that only material had a statistically significant effect on water sorption. Giomer had the highest water sorption value for all storage times; however, it was statistically significant from other materials only after 1 day storage. No statistical significance was found between water sorption values after 1 week and after 4 weeks for all materials tested as $P>0.05$. Nevertheless, sorption values increased with time. Pearson's correlation coefficient revealed no significant correlations between fluoride release and water sorption.

\begin{tabular}{|c|c|c|c|}
\hline & 1 day & 1 week & 4 weeks \\
\hline $\begin{array}{l}\text { Beautifil } \\
\text { flow }\end{array}$ & $1.0020(0.0593)^{a}$ & $0.4140(0.0464)^{b}$ & $0.3165(0.03711)$ \\
\hline $\begin{array}{l}\text { Tetric } \\
\mathrm{N} \text {-flow }\end{array}$ & $0.6013(0.0742)^{\mathrm{b}}$ & $0.3375(0.0241)^{c}$ & $0.0923(0.0834)^{d}$ \\
\hline $\begin{array}{l}\text { G-aenial } \\
\text { Flo }\end{array}$ & $0.5778(0.1826)^{b}$ & $0.3006(0.0940)^{c}$ & $0.0752(0.0196)^{d}$ \\
\hline
\end{tabular}

Means with different letters are significantly different at $P=0.05$

Table 3: Descriptive statistics (mean [standard deviation]) $\left(\mu \mathrm{g} / \mathrm{mm}^{3}\right)$ for water sorption

\begin{tabular}{lccc}
\hline & 1 day & 1 week & 4 weeks \\
\hline Beautifil flow & 25.69 $(4.08)^{\mathrm{a}}$ & $30.87(4.11)^{\mathrm{a}}$ & $32.15(6.79)^{\mathrm{a}}$ \\
Tetric N-flow & $21.23(2.65)^{\mathrm{b}}$ & $27.54(3.73)^{\mathrm{a}}$ & $28.36(3.28)^{\mathrm{a}}$ \\
G-aenial Flo & $18.61(2.17)^{\mathrm{b}}$ & $26.63(4.68)^{\mathrm{a}}$ & $29.81(4.36)^{\mathrm{a}}$ \\
\hline
\end{tabular}

Means with different letters are significantly different at $P=0.05$

\section{DISCUSSION}

The use of flowable resin composites as anterior and posterior restorations has expanded. Increasing their fluoride releasing ability is, therefore, important. Restorative materials should release fluoride with no adverse effects on physico-mechanical properties. It has been recently suggested that fluoride incorporation into nano-filled materials could favor its faster release due to higher surface area to volume ratio. ${ }^{[13]}$ On another aspect, it was found that filler loading is negatively correlated to water sorption. ${ }^{[14]}$ This was the rationale for selecting nano-filled flowable materials to test fluoride release and water sorption in the present study.

All tested materials, in this research, released fluoride but giomer released significantly higher amounts. Therefore, the first null hypothesis should be rejected. Albers ${ }^{[15]}$ suggested that $90 \%$ of the fluoride is released during the $1^{\text {st }}$ week, whereas the remaining $10 \%$ might be released more slowly. Fluoride release was measured after 4 weeks in this study, to detect if measurable amounts of fluoride could still be released from nano-hybrid composites. It was proven that GIC, RMGIC, and nano-ionomers show initial burst effect for fluoride release, which then declines through the $1^{\text {st }}$ week and stabilizes within 3-4 weeks. ${ }^{[13]}$ This can be explained by the rapid elution of fluoride liberated as a result of the acid-base reaction, which takes place on the glass particles surface. However, fluoride-releasing resin composites show no burst effect, but rather a low and constant pattern of fluoride release over time. ${ }^{[13]}$ According to Itota et al..${ }^{[9]}$ the rate of ion release depended on the rate of water sorption and the segmental mobility of polymer chains within the resin phase of the polymerized resin composites. The continued presence of minute amounts of fluoride in the aqueous phase around teeth will reduce the effect of undersaturation conditions when the $\mathrm{pH}$ drops.

Like in previous researches, ${ }^{[2,16,17]}$ deionized water was used as a medium for measuring fluoride release, as it gives an accurate estimate of fluoride ions. A reduced fluoride release was found by Preston et al..$^{[18]}$ and Okada et al..$^{[19]}$ when using artificial saliva. In addition, the protocol followed in the present study was to change the water every $24 \mathrm{~h}$, as recommended by other authors, ${ }^{[2,16,17]}$ to prevent equilibration of fluoride levels. Fluoride determination is based on a concentration gradient mechanism, and the release will stop when equilibrium is reached. 
TISAB II buffer was used in the study to ensure an acidic $\mathrm{pH}$, which is needed to have the best use of the electrode, and for de-complexing of complexed fluoride to determine the total fluoride. Fluoride measurements were done using an ion-specific electrode because it is accurate and gives a direct estimate of free fluoride. ${ }^{[17,18]}$ Nevertheless, manufacturers of electrodes state limitations during their use with minimal fluoride levels and recommend that measurements should only be taken when an output change is of $50-60 \mathrm{mV}$. ${ }^{[20]}$ A limitation when measuring fluoride could be the contamination of TISAB with low amounts of fluoride. An error of 0.05 ppm was determined during fluoride measurements with an electrode.

Fluoride release results revealed that giomer exhibited greater fluoride ion release than both nano-hybrids after all test periods. Fluoride-releasing ability of SPRG particles is the main reason for this finding. However, SPRG particles have an additional source for fluoride release which is the fluoride complexes within their hydrogel layer. ${ }^{[8]}$ Furthermore, acidified water within the hydrogel surrounding the inner glass of SPRG particles facilitates fluoride release through continual dissolution of the fluoride-containing glass core. ${ }^{[21]}$ This differs from nano-hybrid resin composites which release fluoride through a diffusion mechanism, and no acidic treatment of the glass filler particles occurs in their polymerization reaction. ${ }^{[22]}$ Their low fluoride release can be explained by the low amounts of fluorides incorporated in their fillers, low solubility of ytterbium trifluoride in water, low water content, and permeability of the resin composite. ${ }^{[18]}$ This is in agreement with Yap et al., ${ }^{[17]}$ who stated that fluoride release was higher from giomers than other tested materials after 1 week. Naoum et al. ${ }^{[3]}$ found that fluoride released from giomer was more compared to that released from fluoridated resin composites. On the other hand, this finding was in contrast to Itota et al., ${ }^{[9]}$ who revealed that for Heliomolar, a fluoride-containing resin composite, fluoride release was undetectable using an ion selective electrode. They also found no statistical significance in fluorides released from UniFil S (a fluoride containing resin composite) and Beautifil. They attributed this to that fluoride glass within Beautifil has little or no glass ionomer matrix phase because of the lack of any significant acid-base reaction. Since SPGR has been prereacted, water sorption is not critical in the acid-base reaction. A second explanation was that Beautifil has decreased porosity due to the added resin contents.
It was interesting to find that G-aenial Flo released measurable amounts of fluoride although it is a nonfluoridated resin composite. Material Safety Data Sheets are usually incomplete and sometimes misleading. ${ }^{[23]}$ In these sheets, the manufacturers are committed to give information about the main ingredients $(\geq 1 \%)$. Meanwhile, most additives and some monomers are added in concentrations below $1 \%$. This might explain why G-aenial Flo released fluoride though fluoride was not mentioned in the composition by manufacturers.

The type of the resin matrix is a main factor in water sorption of resinous restorations, which may control both water diffusion rate and the amount of sorption in the matrix. ${ }^{[24]}$ The results of water sorption showed a significant difference between giomer and nano-hybrid composites after 1 day storage. Therefore, the second null hypothesis should also be rejected. This result is in agreement with McCabe and Rusby, ${ }^{[7]}$ who found that giomer showed significantly greater water absorption than Fluoride-releasing composite. This result was also in accordance with EL-Sharkawy et al., ${ }^{[24]}$ who revealed that giomer showed higher water sorption than microhybrid composite due to osmotic pressure generated by prereacted glass polyacid zones leading to absorption and swelling.

Several hydrophilic monomers are incorporated in resin composites with the following order in hydrophilicity: TEGDMA > BisGMA > UDMA. Tetric N-Flow contains Bis-GMA, UDMA, and TEGDMA, whereas G-aenial Flo contains UDMA and TEGDMA. This plus the fact that both nano-hybrid resin composites contain glass filers explains why both materials showed close water sorption values. Mohsen et al. ${ }^{[25]}$ explained that water sorption in resin composites containing UDMA will begin by the formation of intramolecular hydrogen bonds between UDMA polymer and strongly bound water. With the progression of the reaction, loosely bound water will interact with intermolecular hydrogen bonds of adjacent polymer chains inducing chain slippage and polymer plasticization. ${ }^{[25]}$

Restorative resinous materials must comply with ISO 4049 and ADA Specification No. 27[26] that water sorption should not exceed $40 \mu \mathrm{g} / \mathrm{mm}^{3}$ after 7 days of water storage. In this study, water sorption measured was below these levels even after 4 weeks. When water sorption exceeds those limits, several restorative material properties would be negatively affected and consequently their clinical behavior and 
biocompatibility. ${ }^{[27]}$ No significant correlation was found between fluoride release and water sorption. This may be attributed to the difference in fluoride release mechanism of the different tested materials. In addition to the difference in the type of the resin matrix between them which is the main factor in water sorption.

A limitation of this study was measuring fluoride release in a neutral environment. Fluoride release increases in an acidic medium which could be the case in the oral cavity. The oral cavity is a challenging environment that cannot be precisely replicated in experimental conditions. However, simulating these conditions could give valuable information.

\section{CONCLUSIONS}

Under the limitations of this study, the following could be concluded: fluoride release is material and time dependent, while water sorption is affected by the type of the material.

\section{Financial support and sponsorship Nil.}

\section{Conflicts of interest}

There are no conflicts of interest.

\section{REFERENCES}

1. Sunico MC, Shinkai K, Katoh Y. Two-year clinical performance of occlusal and cervical giomer restorations. Oper Dent 2005;30:282-9.

2. Dionysopoulos D, Koliniotou-Koumpia E, Helvatzoglou-Antoniades M, Kotsanos N. Fluoride release and recharge abilities of contemporary fluoride-containing restorative materials and dental adhesives. Dent Mater J 2013;32:296-304.

3. Naoum S, Ellakwa A, Martin F, Swain M. Fluoride release, recharge and mechanical property stability of various fluoride-containing resin composites. Oper Dent 2011;36:422-32.

4. Beriat NC, Nalbant D. Water Absorption and HEMA Release of Resin-Modified Glass-Ionomers. Eur J Dent 2009;3:267-72.

5. Mortier E, Gerdolle DA, Dahoun A, Panighi MM. Influence of initial water content on the subsequent water sorption and solubility behavior in restorative polymers. Am J Dent 2005;18:177-81.

6. Sideridou I, Achilias DS, Spyroudi C, Karabela M. Water sorption characteristics of light-cured dental resins and composites based on Bis-EMA/PCDMA. Biomaterials 2004;25:367-76.

7. McCabe JF, Rusby S. Water absorption, dimensional change and radial pressure in resin matrix dental restorative materials. Biomaterials 2004;25:4001-7.

8. Tay FR, Pashley EL, Huang C, Hashimoto M, Sano H, Smales RJ, et al. The glass-ionomer phase in resin-based restorative materials. J Dent Res 2001;80:1808-12.

9. Itota T, Carrick TE, Rusby S, Al-Naimi OT, Yoshiyama M, McCabe JF. Determination of fluoride ions released from resin-based dental materials using ion-selective electrode and ion chromatograph. J Dent 2004;32:117-22.

10. Kiran A, Hegde V. A short term comparative analysis of fluoride release from a newly introduced glass ionomer cement in deionised water and lactic acid. J Int Oral Health 2010;2:71-8.

11. ISO-Standards. Dentistry Polymer-Based Restorative Materials ISO 4049:2009(E). Geneva, Switzerland: International Organization for Standardization; 2009.

12. Al-Qahtani MQ, Salman SB, Helayl AA, Hamdan GA. Effect of immersion media on sorption and solubility of different tooth-colored restoratives. Pak Oral Dent J 2012;32:304-10.

13. Neelakantan P, John S, Anand S, Sureshbabu N, Subbarao C. Fluoride release from a new glass-ionomer cement. Oper Dent 2011;36:80-5.

14. Janda R, Roulet JF, Latta M, Rüttermann S. Water sorption and solubility of contemporary resin-based filling materials. J Biomed Mater Res B Appl Biomater 2007;82:545-51.

15. Albers HF. Tooth Colored Restoratives. UK: Hamilton; 2002. p. 1-4.

16. Attar N, Turgut MD. Fluoride release and uptake capacities of fluoride-releasing restorative materials. Oper Dent 2003;28:395-402.

17. Yap AU, Tham SY, Zhu LY, Lee HK. Short-term fluoride release from various aesthetic restorative materials. Oper Dent 2002;27:259-65.

18. Preston AJ, Mair LH, Agalamanyi EA, Higham SM. Fluoride release from aesthetic dental materials. J Oral Rehabil 1999;26:123-9.

19. Okada K, Tosaki S, Hirota K, Hume WR. Surface hardness change of restorative filling materials stored in saliva. Dent Mater 2001;17:34-9.

20. McCabe JF, Carrick TE, Sidhu SK. Determining low levels of fluoride released from resin based dental materials. Eur J Oral Sci 2002;110:380-4.

21. Attar N, Onen A. Fluoride release and uptake characteristics of aesthetic restorative materials. J Oral Rehabil 2002;29:791-8.

22. Aboush YE, Torabzadeh H. Fluoride release from tooth-colored restorative materials: A 12-month report. J Can Dent Assoc 1998;64:561-4, 568 .

23. Henriks-Eckerman ML, Suuronen K, Jolanki R, Alanko K. Methacrylates in dental restorative materials. Contact Dermatitis 2004;50:233-7.

24. EL-Sharkawy FM, Zaghloul NM, Ell-Kappaney AM. Effect of water absorption on color stability of different resin based restorative materials in vitro study. Int J Comp Mater 2012;2:7-10.

25. Mohsen NM, Craig RG, Filisko FE. The effects of moisture on the dielectric relaxation of urethane dimethacrylate polymer and composites. J Oral Rehabil 2001;28:376-92.

26. ADA Division of Science, ADA Council on Scientific Affairs. Resin-based composites. J Am Dent Assoc 2003;134:510-2.

27. Archegas LR, Caldas DB, Rached RN, Vieira S, Souza EM. Sorption and solubility of composites cured with quartz-tungsten halogen and light emitting diode light-curing units. J Contemp Dent Pract 2008;9:73-80 